\title{
Identification with the neighborhood: Discrimination and neighborhood size
}

\section{Fátima Bernardo \& José-Manuel Palma-Oliveira}

To cite this article: Fátima Bernardo \& José-Manuel Palma-Oliveira (2016): Identification with the neighborhood: Discrimination and neighborhood size, Self and Identity, DOI: 10.1080/15298868.2016.1178665

To link to this article: http://dx.doi.org/10.1080/15298868.2016.1178665

Published online: 05 Jun 2016.

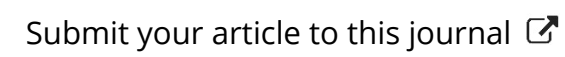

View related articles $\square$

View Crossmark data ¿ 


\title{
Identification with the neighborhood: Discrimination and neighborhood size
}

\author{
Fátima Bernardo ${ }^{a, b, \S ~(D) ~ a n d ~ J o s e ́-M a n u e l ~ P a l m a-O l i v e i r a c ~}$ \\ ${ }^{a}$ Departamento de Psicologia, Universidade de Évora, Évora, Portugal; ${ }^{b} C E S U R$, Universidade de Lisboa, Lisboa, \\ Portugal; 'Faculdade de Psicologia, Universidade de Lisboa, Lisboa, Portugal
}

\begin{abstract}
This paper analyzes the impact of a geographical social grouping (neighborhood) and its relative perceived size in the spontaneous group's identification level and place satisfaction, as well as the intensity of and motives for discrimination against inhabitants of other places. Two studies are presented: an experimental one using the minimal group categorization paradigm and an onsite investigation of a city neighborhood. Consistent with the predictions, the results showed that smaller neighborhoods reported higher identification and satisfaction with the place of residence, as well as higher discrimination of other neighborhoods. In line with the optimal distinctiveness theory (ODT), the findings showed that the motivation for discrimination varies as a function of the in-group size. Thus, the members of larger groups discriminate by increasing the differentiation between the in-group and the out-group, whereas the members of smaller groups increased the value of the in-group. Furthermore, the results were consistent with a social identity theory and ODT explanation of diverse research that shows the non-trivial nature of geographical bounded social grouping and its importance in a diverse set of contexts and its impact in inter-neighborhood relationships.
\end{abstract}

ARTICLE HISTORY

Received 3 November 2014

Accepted 4 April 2016

Published online 6 June 2016

\section{KEYWORDS}

Social Identity; discrimination; neighborhood

\section{Introduction}

More than the mere location of human activity, places are seen as fundamental components of personal identity (Proshansky, Fabian, \& Kaminoff, 1983). Indeed, places can also be a basis for social categorization (e.g., Bernardo \& Palma-Oliveira, 2012, 2013; Bonaiuto, Breakwell, \& Cano, 1996; Droseltis \& Vignoles, 2010; Lewicka, 2010) in the sense that people define themselves as belonging to a geographically defined group. This implies that, as a part of the process of self-categorization, individuals attribute to places, and the people who live in them, including themselves, a certain degree of similarity of psychosocial characteristics. Accordingly, places are social constructions with shared social meanings and not merely a scenario for interaction. Identification with place, therefore, contributes to one's social identity and to understanding group processes. Thus, we can assume that just like identification with a social group, place identification affects the perception and behavior of people 